Original

\title{
The Effects of D-galactosamine- or Carbon Tetrachloride- Induced Regeneration on Induction of Rat Liver Cell Foci in a Model for Detection of Initiation Activities of Chemicals
}

\author{
Hiroki Sakai ${ }^{1,2}$, Atsushi Inagami ${ }^{2}$, Akihiro Hirata ${ }^{2}$, Tetsuya Tsukamoto ${ }^{1}$, \\ Kiyoshi Kobayashi ${ }^{3}$, Masakuni Degawa ${ }^{4}$, Norimitsu Shirai ${ }^{1,2}$, Takeshi Iidaka ${ }^{1,2}$, \\ Tokuma Yanai ${ }^{2}$, Toshiaki Masegi ${ }^{2}$, and Masae Tatematsu ${ }^{1}$ \\ ${ }^{1}$ Laboratory of Oncological Pathology, Aichi Cancer Center Research Institute, Kanokoden 1-1, Chikusa-ku, Nagoya \\ 464-8681, Japan \\ ${ }^{2}$ Department of Veterinary Pathology, Gifu University, Yanagido 1-1, Gifu, 501-1193, Japan \\ ${ }^{3}$ Toxicology Laboratory, Research Center, Mitsubishi-Tokyo Pharmaceuticals, Inc., 5-100, Yana, Kisarazu, Chiba \\ 292-0812, Japan \\ ${ }^{4}$ Department of Molecular Toxicology, School of Pharmaceutical Sciences, University of Shizuoka, 52-1 Yada, \\ Shizuoka, 422-8526, Japan
}

\begin{abstract}
The effects of D-galactosamine (D-gal) and carbon tetrachloride $\left(\mathrm{CCl}_{4}\right)$ administration on induction of liver cell proliferation in a medium term liver bioassay for detection of initiation activity of 1,2-dimethylhydrazine (DMH) were investigated with special emphasis on kinetics of cell proliferation and cytochrome P450 (CYP) expression. In experiment I, fluctuation of cell proliferation and CYP 2E1, which is one of the enzymes involved in bioactivation DMH to ultimate form, levels of liver cells after D-gal administration $\left(4000 \mathrm{mg} / \mathrm{kg}\right.$, i.g.) or $\mathrm{CCl}_{4}$ administration ( $1 \mathrm{ml} / \mathrm{kg}$, i.g.) was analyzed by bromodeoxyuridine labeling and western blotting, respectively. In experiment II, induction of glutathione S-transferase placental form (GST-P)-positive foci by DMH in a model for detection of initiation activities using D-gal or $\mathrm{CCl}_{4}$ administration as a toxicity-regeneration dependent proliferative stimulus was evaluated. Although high BrdU labeling indices continued from $36 \mathrm{~h}$ to $72 \mathrm{~h}$ after D-gal and $\mathrm{CCl}_{4}$ treatment, cell proliferation after intragastric D-gal administration was very low compared with the $\mathrm{CCl}_{4}$ case. Decrease of CYP 2E1 apoprotein content in the microsomes was slight after D-gal administration, whereas decrease up to about $40 \%$ of the control level was evident from $12 \mathrm{~h}$ until $60 \mathrm{~h}$ after $\mathrm{CCl}_{4}$. When the carcinogen was injected $60 \mathrm{~h}$ after D-gal administration, there was appreciable increase in the area and numbers of GST-P positive foci, similar to the case with $\mathrm{CCl}_{4}$ administration. Sensitivities for detection of initiation activity with intragastric $\mathrm{D}$-gal or $\mathrm{CCl}_{4}$ administration were equal, despite the kinetics of cell proliferation and CYP $2 \mathrm{E} 1$ being very different. With $\mathrm{CCl}_{4}$ administration, initiation depended on fluctuation of CYP 2E1, reversibly in intragastric D-gal treatment, initiation depended on cell kinetics.
\end{abstract}

(J Toxicol Pathol 2002; 15: 13-18)

Key words: D-galactosamine, carbon tetrachloride, intiation, CYP 2E1, rats, liver

\section{Introduction}

For detection of initiation activity in the relatively short term, evaluation of induction of glutathione-S transferase placental form (GST-P) positive foci in rat liver has been widely used ${ }^{1-3}$. Cell proliferation and bioactivation of procarcinogens are important parameters for the initiation process $^{4}$ and induction of liver regeneration is the first step in

Received: 9 October 2001, Accepted: 27 November 2001

Mailing address: Masae Tatematsu, Laboratory of Oncological

Pathology, Aichi Cancer Center Research Institute, Kanokoden 1-1,

Chikusa-ku, Nagoya 464-8681, Japan

TEL: 81-52-762-2972 FAX: 81-52-762-2971

E-mail:mtatemat@aichi-cc.pref.aichi.jp induction of GST-P positive foci for detection of initiation activity $^{3}$. Two-thirds partial hepatectomy has been utilized for induction of liver cell proliferation ${ }^{5}$, but this requires surgical expertise and presents problems, especially when with large numbers of rats. In contrast, chemical hepatectomy achieved with hepatotoxicant administration is very simple. Carbon tetrachloride $\left(\mathrm{CCl}_{4}\right)$ has been employed for this purpose $e^{1,2}$, but causes hepatic necrosis in centrilobular areas where expression of cytochrome P450 (CYP) is strongest ${ }^{6}$, so that bioactivation of carcinogens may be effected ${ }^{7}$. D-galactosamine (D-gal) is another hepatotoxicant with a different mechanism of liver injury from $\mathrm{CCl}_{4}$. A toxic dose induces cell proliferation ${ }^{8,9}$, therefore, D-gal administration will be utilized as cell 
proliferative stimulus in a model for detection of initiation activities of chemicals. However, the effect of liver regeneration induced by $\mathrm{D}$-gal administration on initiation of carcinogenesis has been unclear.

In the present study, we therefore compared the effects of intragastric D-gal- and $\mathrm{CCl}_{4}$-induced liver cell proliferation in a medium term liver bioassay for detection of initiation activity of 1,2-dimethylhydrazine (DMH), concentrating attention on cell kinetics and expression of CYP 2E1 which is one of the enzymes involved in bioactivation DMH to ultimate carcinogens ${ }^{10}$.

\section{Materials and Methods}

\section{Animals}

The animals, male F344 rats (Charles River Japan Inc., Atsugi), were housed five per plastic cage on wood chips for bedding under constant conditions (12 h light/dark cycle,
$60 \%$ humidity at $22 \pm 2{ }^{\circ} \mathrm{C}$ ) on Oriental NMF diet (Oriental Yeast Co., Tokyo) and tap water ad libitum. They were acclimatized for one week before the start of experiments, at which time they were 7 weeks old and weighed 150-170 g.

\section{Chemicals}

DMH was purchased from Tokyo Kasei Co. (Tokyo), $\mathrm{CCl}_{4}$ and D-galactosamine hydrochloride from Wako Pure Chemical Industries Ltd. (Osaka), and bromodeoxyuridine (BrdU) from Sigma Chemical Co. (St. Louis, MO, USA). The diet containing $0.015 \%$ of 2-acetylaminofluorene (2AAF) was purchased from Japan Clea Co., Ltd. (Osaka, Japan).

\section{Experimental protocols (Fig. 1)}

In experiment I (Fig. 1A), for the analysis of cell proliferation kinetics of liver cells after D-gal administration (4000 mg/kg, i.g.) or $\mathrm{CCl}_{4}$ administration ( $1 \mathrm{ml} / \mathrm{kg}$, i.g.),

A

\begin{tabular}{llllllll}
0 & 12 & 24 & 36 & 48 & 60 & 72 \\
\hline $\begin{array}{l}\text { or } \\
8\end{array}$ & $\mathrm{~s}$ & $\mathrm{~s}$ & $\mathrm{~s}$ & $\mathrm{~s}$ & $\mathrm{~s}$ & $\mathrm{~s}$
\end{tabular}$/ \underbrace{\text { 7days }}_{\mathrm{s}}$

$\Delta$ : D-galactosamine in saline $4000 \mathrm{mg} / \mathrm{kg} \mathrm{b.w.} \mathrm{i.g.}$

$\triangle: \mathrm{CCl}_{4} \quad 1.0 \mathrm{ml} / \mathrm{kg} \quad$ b.w. i.g.

S : Sacrifice before one hour BrdU $100 \mathrm{mg} / \mathrm{kg}$ b.w. i.p.

$\mathrm{B}$

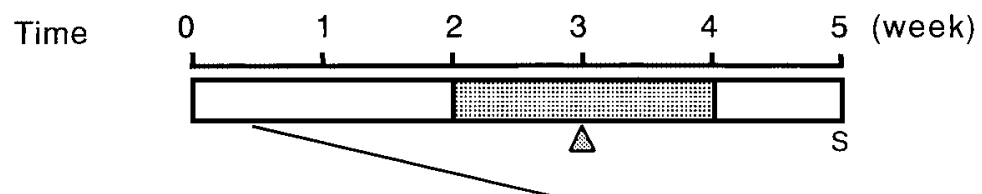

Time $\quad \begin{array}{lllllll}0 & 12 & 24 & 36 & 48 & 60 & 72\end{array}$

\begin{tabular}{ll|l|l|l|l|} 
D-gal 12 & \\
\hline
\end{tabular}

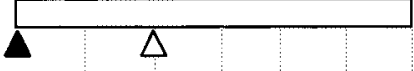

D-gal 36

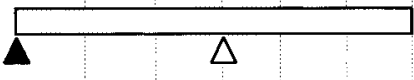

$\Delta$ : D-galactosamine in saline

D-gal 48

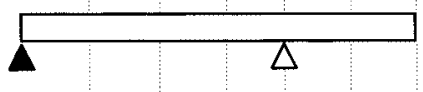
$4000 \mathrm{mg} / \mathrm{kg}$ b.w. i.g.

$\triangle: \mathrm{CCl}_{4} \quad 1.0 \mathrm{ml} / \mathrm{kg} \quad$ b.w. i.g.

D-gal 60

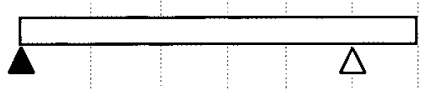

$\triangle:$ DMH $10 \mathrm{mg} / \mathrm{kg}$ b.w. i.g.

D-gal 72

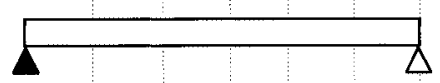

: $0.015 \%$ 2-AAF in the diet

S : Sacrifice

D-gal control

$\mathrm{CCl} 4$

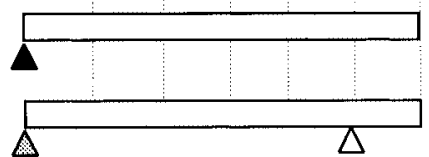

Fig. 1. Schematic representation of the protocols for (A) experiment I and (B) experiment II. See Materials and Methods for further details. 
groups of rats were given an i.p. injection of BrdU (100 mg/ $\mathrm{kg}) 1 \mathrm{~h}$ before sacrifice, 12, 24, 36, 48, 60, $72 \mathrm{~h}$, and 7 days after D-gal administration as in Fig. 1A. Liver slices were fixed in 10\% neutral buffered formalin for BrdU. For microsome analysis, liver was frozen by liquid nitrogen and stored at $-80^{\circ} \mathrm{C}$ until prepared for microsome.

In experiment II (Fig. 1B), in order to determine correlates among cell proliferation, kinetics of CYP 2E1 and induction of GST-P-positive foci, rats were divided into six groups as shown in Fig. 1B, given doses of DMH $(10 \mathrm{mg} / \mathrm{kg}$ wt. i.g.) administered at 12, 24, 36, 48, 60, and $72 \mathrm{~h}$ after Dgal administration, respectively. The control group received no $\mathrm{DMH}$ administration after D-gal i.g. The $\mathrm{CCl}_{4}$ administration group was administered $\mathrm{CCl}_{4}$ instead of Dgal, and received DMH i.g. $60 \mathrm{~h}$ after administration at the high point of susceptibility to induction of GST-P-positive foci reported previously ${ }^{2}$. Subsequently, diet containing $0.015 \%$ of $2-\mathrm{AAF}$ was given for the following 2 weeks. Three weeks after DMH administration, all animals received a dose of $\mathrm{CCl}_{4}(0.8 \mathrm{ml} / \mathrm{kg} \text { body wt. i.g. })^{5}$. At the end of week 5 the survivors were killed and liver slices were fixed in 10\% neutral buffered formalin for immunohistochemical examination of GST-P-positive foci. All animals were handled In accordance with the guidelines for animal experimentation of the Faculty of Agriculture, Gifu University.

Soudium dodecyl sulfate (SDS)-polyacrylamide gel electrophoresis and immunoblot analysis for CYP 2E1protein

Liver microsomes after $\mathrm{D}$-gal or $\mathrm{CCl}_{4}$ administration were prepared essentially as described by Burke et al. ${ }^{11}$. Briefly, livers obtained in experiment I were transferred into $0.25 \mathrm{M}$ glycerol $/ 50 \mathrm{mM}$ Tris $\mathrm{pH} 7.4$ and homogenized with a glass Potter-Elvehjem type homoginizer with a Teflon pestle. Each liver homogenate was centrifuged at $13,500 \mathrm{~g}$ for 20 minutes and the supernatant was re-centrifuged at $105,000 \mathrm{~g}$ for 60 minutes $^{12}$. The resulting pellet of the microsomal fraction, was washed once in $0.15 \mathrm{M} \mathrm{KCl} / 10$ $\mathrm{mM}$ Tris $\mathrm{pH}$ 7.6, centrifuged and processed for the BioRad DC protein assay (BioRad, Hercules, USA) based on Lowry's method ${ }^{13}$. Microsomal preparations were snap frozen in liquid nitrogen and stored at $-80^{\circ} \mathrm{C}$ until use.

Liver microsomes were separated on a $10 \%$ SDSpolyacrylamide ge ${ }^{14}$ and blotted on to Hybribond $\mathrm{P}$ (Amersham, Buckinghamshire, England) in 20\% methanol, $400 \mathrm{mM}$ glycine, $50 \mathrm{mM}$ Tris- $\mathrm{HCl} \mathrm{pH} 8.3$ at $4^{\circ} \mathrm{C}$ for $60 \mathrm{~V}$ for $4 \mathrm{~h}$. CYP 2E1 was detected with an antibody kit purchased from Amersham using the ECL detection system as recommended by the manufacturer (Amersham). A positive control for CYP 2E1 was added as supplied by the manufacturer. Quantitation of the results was performed as described by Trautwein et al. ${ }^{12}$

\section{Immunohistochemistry and analysis of sections}

The avidin-biotin complex method ${ }^{15}$ was used to demonstrate GST-P-positive foci using anti-GST-P-IgG
(MBL, Nagoya), BrdU-labeled cells with anti-BrdU IgG (DAKO Japan Co., Kyoto) and expression of CYP 2E1 with anti-CYP 2E1 apoprotein IgG (Chemicon International, Inc., Temecula, CA). The numbers of foci $>0.1 \mathrm{~mm}$ in diameter and the total areas of liver sections examined were assessed as detailed previously ${ }^{1-3}$. The generation of BrdU labeling indices were performed as described previously ${ }^{2}$. The significance of differences in the quantitative data from experiment II was statistically evaluated using ANOVA.

\section{Results}

Cell proliferation kinetics and changes of CYP 2E1 protein contents Hepatic injury by $\mathrm{CCl}_{4}$ administration resulted in centri-lobular necrosis (Fig. 2). At $36 \mathrm{~h}$ after $\mathrm{CCl}_{4}$ administration, necrosis was maximal and the histological architecture had regained a normal appearance at one week thereafter. D-gal-administration induced scattered necrosis with infiltration of inflammatory cells at $36 \mathrm{~h}$ after administration (Fig. 2) with recovery again within one week. The data for liver cell proliferation kinetics are summarized in Fig. 3A. Label incorporation after $\mathrm{CCl}_{4}$ administration increased until $60 \mathrm{~h}$. High labeling indices (approximately $20 \%$ to $30 \%$ of cells positive for $\mathrm{BrdU}$ ) continued from $36 \mathrm{~h}$ to $72 \mathrm{~h}$. There were BrdU-incorporated hepatocytes in the periportal area at high proliferating time. In contrast, cell proliferation after D-gal administration was comparatively low, the mean BrdU index being about $3 \%$ of cell positive at $48 \mathrm{~h}$ after the treatment, elevation continuing until $72 \mathrm{~h}$. The BrdU-incorporated hepatocytes localized also in the periportal area at $48 \mathrm{~h}$ after D-gal treatment.

The data for CYP 2E1 apoprotein content in the microsomal proteins are summarized in Fig. 3B. After $\mathrm{CCl}_{4}$ administration, CYP 2E1 apoprotein contents decreased up to about $40 \%$ of control from $12 \mathrm{~h}$ until $60 \mathrm{~h}$ after. On the other hand, onlylight decrease at $12 \mathrm{hrs}$ and 7 days after Dgal administration, but not to less than $70 \%$ of the control level. Immunohistochemically, the CYP 2E1-positive cells was in the centrilobular area of normal rat liver and the pattern of CYP 2E1 positive cells did not change with time after D-gal administration. Contrastively, most hepatocytes were negative 12 to $48 \mathrm{hrs}$ after $\mathrm{CCl}_{4}$ administration and staining recovered after 7 days.

\section{Induction of GST-P positive foci}

Data for the area and numbers of GST-P positive foci per unit area of liver section are summarized in Fig. 4. When given $60 \mathrm{~h}$ after D-gal administration, there was appreciable increase of area and numbers of GST-P positive foci. The area and number of GST-P-positive foci at 12, $60 \mathrm{~h}$ after Dgal and the group with $\mathrm{CCl}_{4}$ administration were significantly elevated compared with the controls, and the area of GST-P-positive foci at $60 \mathrm{hr}$ after D-gal was significantly higher than that of the group with $\mathrm{CCl}_{4}$ administration, however, numbers of GST-P-positive foci were not significantly different between animals at $60 \mathrm{~h}$ after D-gal and animals with $\mathrm{CCl}_{4}$ administration. 


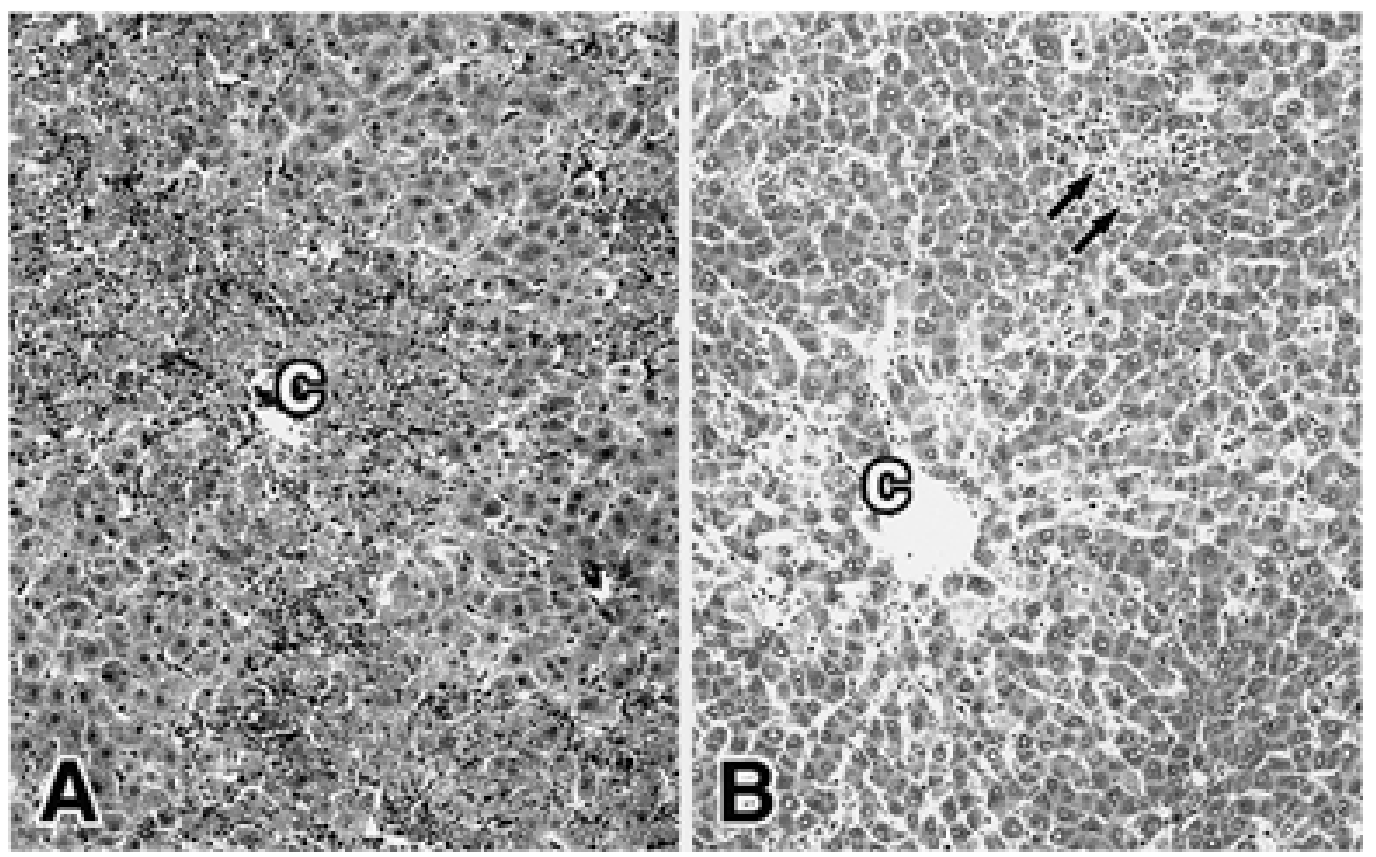

Fig. 2. Liver sections from animals treated with $\mathrm{CCl}_{4}(\mathrm{~A})$ or D-gal (B) in experiment I. A, Severe centri-lobular necrosis in a liver at $36 \mathrm{~h}$ after $\mathrm{CCl}_{4}$ i.g. B, Scattered necrosis with infiltration of inflammatory cells (arrows) in a periportal area at $36 \mathrm{~h}$ after D-gal i.g. C, central vein. $\times 37$.
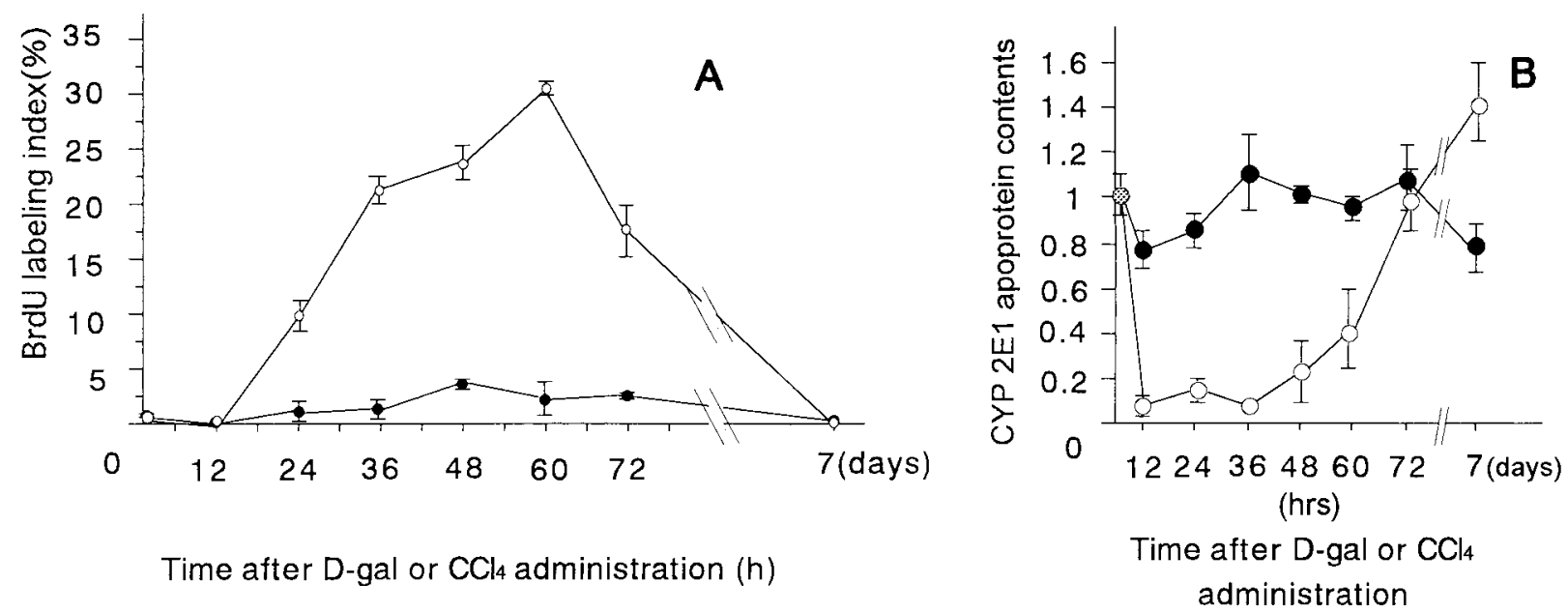

Fig. 3. BrdU labeling indices (A) and CYP 2E1 apoprotein contents (B) in the livers of rats at various times after D-gal (closesd circles) and $\mathrm{CCl}_{4}$ (open circles) administration. CYP 2E1 values are relative to the control level as 1. Data are mean $\pm \mathrm{SD}$ for 5 animals in each group.

\section{Discussion}

In the present study the proliferative period after intragastric D-gal administration was from $48 \mathrm{~h}$ to $72 \mathrm{~h}$, similar to the case recieving $\mathrm{CCl}_{4}$ treatment ${ }^{1,2}$ but the degree of induction of proliferation was very much lower ${ }^{1,2}$. In spite of this, the numbers of GST-P positive foci were not significantly different as compared with the $\mathrm{CCl}_{4}$ group. Dgal traps uracil nucleotides by its toxic intermediary metabolites (UDP-galactosamine and UDP-glucosamine) in rat liver ${ }^{16}$ and induces depletion of hepatic UTP, UDPglucose and UDP-galactose which are essential materials in biosynthesis of macromolecules such as nucleic acids. Consequently, organelle injury and necrosis of hepatocytes occur ${ }^{17}$. $\mathrm{CCl}_{4}$-induced hepatic necrosis is also caused by metabolic intermediates including trichloromethyl radicals and cytochrome $\mathrm{P} 450$ associated with bioactivation of carcinogen is reduced ${ }^{7}$. The radicals bind to CYP 2E1 which 

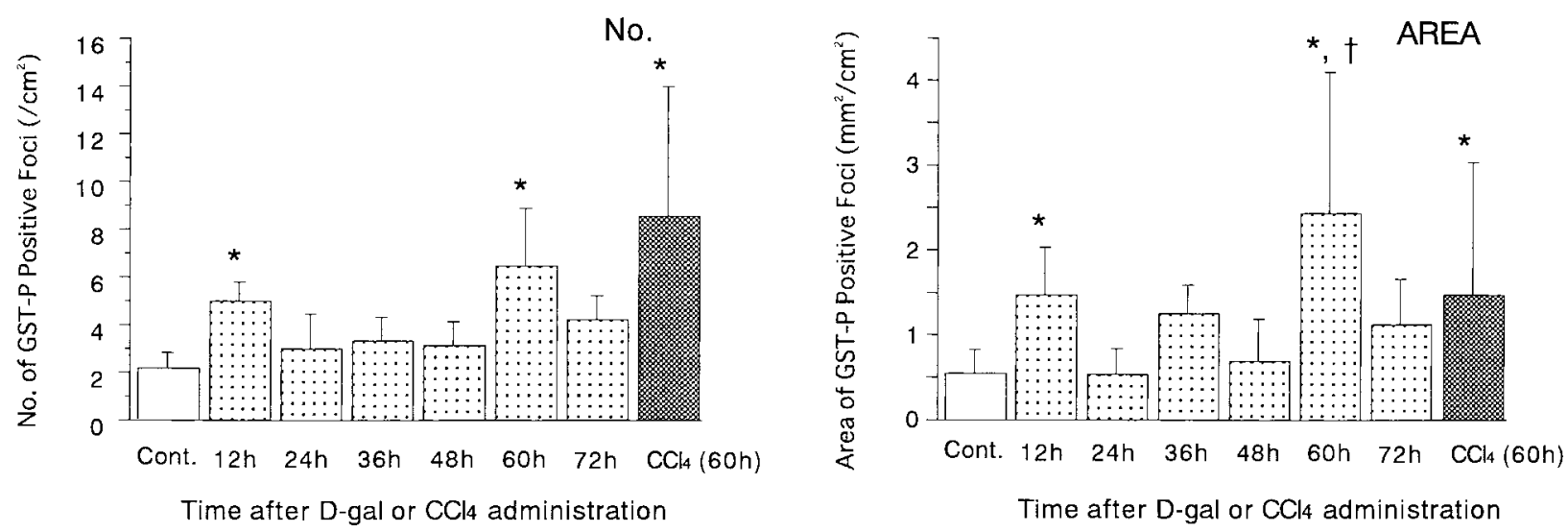

Fig. 4. Numbers and areas of GST-P-positive liver cell foci $>0.1 \mathrm{~mm}$ in diameter in experiment II. Data are mean \pm SD values for $7-11$ animals in each group. ${ }^{*} \mathrm{P}<0.05$ as compared with the group without $\mathrm{DMH}$ administration (Cont.). ${ }^{*} \mathrm{P}<0.05$ as compared with the $\mathrm{CCl}_{4}$ administration group.

is in fact responsible for their activation, degrading and inactivating the enzyme (suicide metabolism) ${ }^{7}$ while causing necrosis of the expressing cells. Necrosis induced by D-gal administration has been reported to predominate in the periportal areas ${ }^{17}$, and therefore reduction of metabolic enzymes localized in cetrilobular areas such as cytochrome P450 is much less. The present quantification by western blotting demonstrated decrease of CYP 2E1 apoprotein content after D-gal administration to be slight (up to approximately $30 \%$ ). In our study, the centrilobular pattern of CYP 2E1 positive cells did not change with time after Dgal administration. Therefore, necrosis induced by intragastric D-gal administration did not influent to CYP $2 \mathrm{E} 1$ contents and localization. In contrast, CYP 2E1 apoprotein contents until $60 \mathrm{hr}$ after $\mathrm{CCl}_{4}$ administration were decreased markedly. For detection for initiation with $\mathrm{CCl}_{4}$ administration in experiment II, we earlier demonstrated that the $60 \mathrm{~h}$ time point is most effective for carcinogen application ${ }^{2}$. Thus, intragastric D-gal administration would be expected to have less suppressive effects on bioactivation of DMH by CYP 2E1 than $\mathrm{CCl}_{4}$, counterbalancing the differential regarding proliferation kinetics. However, the route of D-gal administration in this study was intragastric administration similar to $\mathrm{CCl}_{4}$ treatment, because we wanted to avoid the influence of difference of administrating routes. In previous reports of hetatotoxicity, lower dose of D-gal was administrated by intraperitoneal injection ${ }^{16-18}$. Therefore, there will be a need for comparing the difference of administrating routes of Dgal hereafter.

The area of GST-P positive foci with DMH timed at 60 $\mathrm{h}$ after D-gal administration was significantly higher than the value with $\mathrm{CCl}_{4}$ administration. Selection pressure on GST$\mathrm{P}$ positive cells by $2-\mathrm{AAF}-\mathrm{CCl}_{4}$ treatment should be equal, therefore much of the difference in area might be caused by proliferation of GST-P positive cells in the period prior to 2AAF exposure.
Acknowledgement: This work was supported in part by Grants-in-Aid for Science Research on Priority Areas from the Ministry of Education, Science, Sports, Culture and Technology of Japan and CREST (Core Research for Environmental Science and Technology) of the Japan Science and Technology Corporation.

\section{References}

1. Kobayashi K, Mutai M, Goto K, Inada K, Tsukamoto T, Nakanishi H, and Tatematsu M. Effects of carbon tetrachloride administration on initiation of liver cell foci by the non-hepatocarcinogens N-methyl-N'-nitro-Nnitrosoguanidine (MNNG) and benzo(a)pyrene (B(a)P). Cancer Lett 1997; 118: 55-60.

2. Sakai H, Tsukamoto T, Yamamoto M, Yanai T, Masegi T, Inada K, Nakanishi H, and Tatematsu M. Summation of initiation activities of low doses of the nonhepatocarcinogen 1,2-dimethylhydrazine in the liver after carbon tetrachloride administration. Cancer Lett 2000; 148: 59-63.

3. Tezuka N, Tada M, Kojima M, Nakanishi H, Mori A, and Tatematsu M. Effects of partial hepatectomy on initiation of liver cell foci by 4-nitroquinoline 1-oxide, a nonhepatocarcinogen, and generation of DNA adducts in rats. Cancer Lett 1995; 89: 89-94.

4. Lijinsky W. A view of the relation between carcinogenesis and mutagenesis. Environ Mol Mutagen 1989; 14: 78-84.

5. Tsuda H, Lee G, and Farber E. Induction of resistant hepatocytes as a new principle for a possible short-term in vivo test for carcinogens. Cancer Res 1980; 40: 1157-1164.

6. Yasuda M, Okabe T, Itoh J, Takekoshi S, Hasegawa H, Nagata H, Osamura RY, and Watanabe K. Differentiation of necrotic cell death with or without lysosomal activation: application of acute liver injury models induced by carbon tetrachloride $\left(\mathrm{CCl}_{4}\right)$ and dimethylnitrosamine $(\mathrm{DMN})$. J Histochem Cytochem 2000; 48: 1331-1339.

7. Wang PY, Kaneko T, Tsukada H, Nakano M, Nakajima T, and Sato A. Time courses of hepatic injuries induced by 
chloroform and by carbon tetrachloride: Comparison of biochemical and histopathological changes. Arch Toxicol 1997; 71: 638-645.

8. Ito N, Imaida $\mathrm{K}$, de Camargo JL, Takahashi $\mathrm{S}$, Asamoto M, and Tsuda H. A new medium-term bioassay system for detection of environmental carcinogens using diethylnitrosamine-initiated rat liver followed by Dgalactosamine treatment and partial hepatectomy. Jpn J Cancer Res 1988; 79: 573-575.

9. Tsuda H, Masui T, Ikawa E, Imaida K, and Ito N. Compared promoting potential of D-galactosamine, carbon tetrachloride and partial hepatectomy in rapid induction of preneoplastic liver lesions in the rat. Cancer Lett 1987; 37: 163-171.

10. Sohn OS, Ishizaki H, Yang CS, and Fiala ES. Metabolism of azoxymethane, methylazoxymethanol and $\mathrm{N}$ nitrosodimethylamine by cytochrome P450IIE1. Carcinogenesis 1991; 12: 127-131.

11. Burke MD and Mayer RT. Ethoxyresorufin: direct fluorimetric assay of a microsomal O-dealkylation which is preferentially inducible by 3-methylcholanthrene. Drug Metab Dispos 1974; 2: 583-588.

12. Trautwein C, Rakemann T, Obermayer-Straub P, Niehof M, and Manns MP. Differences in the regulation of cytochrome
P450 family members during liver regeneration. J Hepatol 1997; 26: 48-54.

13. Lowry OH, Rosebrought NJ, Farr AL, and Randall FJ. Protein measurement with the folin phenol reagent. J Biol Chem 1951; 193: 265-275.

14. Laemmli UK. Cleavage of structural proteins during the assembly of the head of bacteriophage T4. Nature 1970; 227: 680-685.

15. Hsu SM, Raine L, and Fanger H. Use of avidin-biotinperoxidase complex (ABC) in immunoperoxidase techniques: a comparison between $\mathrm{ABC}$ and unlabeled antibody (PAP) procedures. J Histochem Cytochem 1981; 29: $577-580$.

16. Abdul-Hussain SK and Mehendale HM. Ongoing hepatocellular regeneration and resiliency toward galactosamine hepatotoxicity. Arch Toxicol 1992; 66: 729742.

17. Decker K and Keppler D. Galactosamine induced liver injury. In: Progress in Liver Diseases, H Popper and S Fenton (eds), New York: Grune \& Stratton, 183-199, 1972.

18. Murase T, Masuda R, Aoi K, Sawamura T, Shiozaki Y, and Sameshima $\mathrm{Y}$. The effect of galactosamine on rat liver cytochrome P-450 activities. Jpn J Pharmacol 1985; 37: 151-158. 